\title{
Correction to: Inhibition of Dectin-1 Ameliorates Neuroinflammation by Regulating Microglia/Macrophage Phenotype After Intracerebral Hemorrhage in Mice
}

\author{
Xiongjie Fu ${ }^{1}$. Hanhai Zeng ${ }^{1}$ Jikuang Zhao ${ }^{1,2}$. Guoyang Zhou ${ }^{1}$. Hang Zhou ${ }^{1}$. Jianfeng Zhuang ${ }^{1}$. Chaoran Xu ${ }^{1}$.

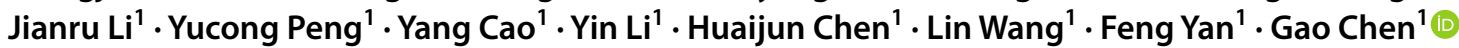

Published online:3 July2021

(C) The Author(s), under exclusive licence to Springer Science+Business Media, LLC part of Springer Nature 2021

\section{Correction to: Translational Stroke Research}

https://doi.org/10.1007/s12975-021-00889-2

Unfortunately, there was an error in Figure 1b. The last one histogram and the third histogram in Figure 1b were repeated. The authors apologize for the mistake. A new Figure 1 has been uploaded.

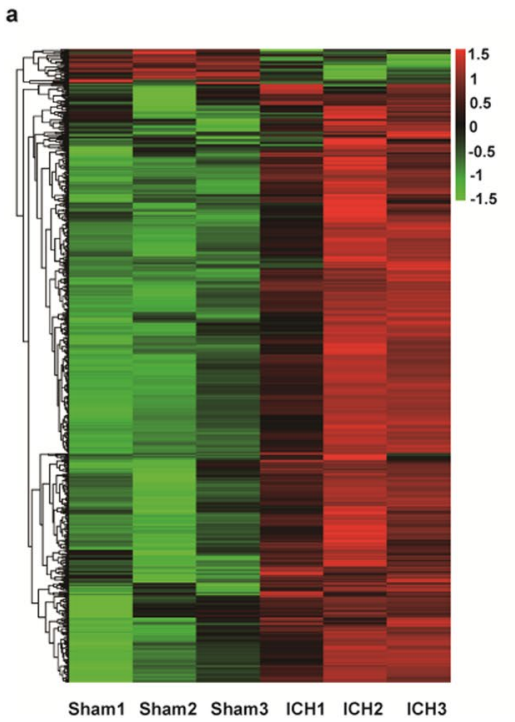

The original article can be found online at https://doi.org/10.1007/ s12975-021-00889-2.

\section{Feng Yan}

yan.feng7@163.com

$\triangle$ Gao Chen

d-chengao@zju.edu.cn

1 Department of Neurosurgery, Second Affiliated Hospital, School of Medicine, Zhejiang University, Jiefang Road 88th, Hangzhou 310016, China

2 Department of Neurosurgery, Ningbo First Hospital, Ningbo Hospital, Zhejiang University School of Medicine, Ningbo, China
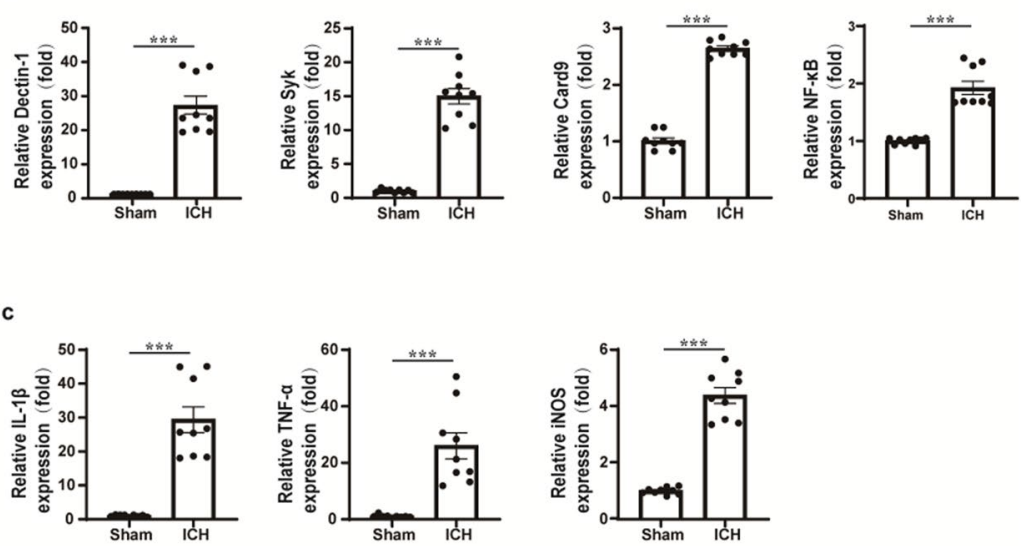

The original article has been corrected.

Publisher's Note Springer Nature remains neutral with regard to jurisdictional claims in published maps and institutional affiliations. 